\title{
Morphometric Characteristics of the Conal Coronary Artery
}

\author{
Ivan Stankovic*, Milica Jesic
}

\begin{abstract}
The right conal (conus) artery either presents as the first ventricular branch of the right coronary artery (RCA) or arises directly from the aorta, in which case, it is considered the third coronary artery (TCA). Morphometric characterization of this artery is important for interpretation of coronarography, surgical revascularization of myocardium and embryological interpretations. Eight out of 23 hearts presented the TCA $(34.8 \%)$. The difference in the frequency of the TCA between the sexes was statistically insignificant $(p>0.05)$. In all the specimens, the ostium of the TCA was to the left of and superior to the ostium of the RCA. The supernumerary (third) coronary artery formed Vieussens' arterial ring in 50\% of the cases with the TCA, while the conal branch of the RCA formed the anastomosis with the conal branch at a higher frequency (63\% of the cases). The ratio of external diameters of the RCA and TCA was $2.84 \pm 0.78$, while the ratio of external diameters of the RCA and its conal branch was 2.61 \pm 0.74 . The difference in the ratios was statistically insignificant $(\mathbf{p}>0.05)$. There were no findings indicating that the presence of the TCA could be detrimental or advantageous when compared to the classical coronary scheme (right and left coronary arteries originating from the aortic sinuses). Based solely on the TCA's morphological features, there is insufficient evidence to suggest that the presence of the TCA per se, is associated with a known clinical or disease state.
\end{abstract}

KEY WORDS: conal artery, supernumerary coronary artery, and third coronary artery.

\section{INTRODUCTION}

The right conal (conus) artery is the first ventricular branch of the right coronary artery (RCA). It most frequently arises from the proximal part of the RCA. It can also arise from the right aortic sinus, in which case, it is considered the third coronary artery (TCA). It is also called the right infundibular branch, the supernumerary coronary artery, the right Vieussens artery and the adipose artery (1). The right conal artery usually forms an anastomosis with the likewise branch of the left coronary artery (LCA), This anastomosis lies on the distal part of the arterial conus and pulmonary trunk and is known as the Vieussens' arterial ring. The functional significance of this anastomosis is still under

* To whom correspondence should be addressed: Ivan Stankovic, Narodnog heroja 36, 17500 Vranje Serbia and Montenegro email: ivanstankovic@fastmail.fm the question. However, several authors have proposed that it functions as an important collateral path between the right and left coronary arteries $(1,2)$.

Embryological investigations have offered a few hypotheses about coronary arteries' development but none, of which, have been directly related to the TCA. Several studies have suggested that coronary arteries did not grow out of the aorta but grew into the aorta from the proximal peritruncal circles of coronary arterial vasculature $(3,4,5)$.

According to (6), the main coronary arteries originated from three "proximal" vascular circles. These include the atrioventricular circle, which formed the right coronary artery and the circumflex branch of the left coronary artery, the interampullary circle, which gave off the anterior and posterior descending coronary arteries, and the conotruncal circle, also known as the 
embryological circle of Vieussens, which communicated with the lumen of the truncus arteriosus by way of the coronary ostia. The conotruncal circle also anastomosed with the other two coronary arterial circles, thereby establishing the definitive coronary arterial circulation. In addition, the coronary arteries trunks' forerunners, which arose from the vascular circles, extended towards the aorta and grew into it (3). Our research aim is to improve the current morphometric characterization of the conal artery which could be important in the interpretation of coronarography, surgical revascularization of myocardium and embryological interpretations.

\section{METHODS}

23 hearts from cadavers of adult individuals of both sexes (10 males and 13 females), white race, and age between 21 and 76 (mean age $48 \pm 15$ years) were used in this investigation. Fifteen out of the 23 specimens belonged to the Institute of Anatomy, School of Medicine, University of Belgrade. These specimens were obtained from the subjects who had donated their body to the Institute. The medical records of these donors were not accessible. The other 8 specimens were obtained after the necropsies performed at the Institute of Forensic Medicine in Belgrade. They belonged to so-called healthy individuals whose deaths were accidental and not related to cardiac disease. Detailed morphological examinations were carried out at the Institute of Anatomy in Belgrade. The hearts obtained after necropsies were fixed in $10 \%$ formaldehyde solution for two weeks. The specimens from the Institute of Anatomy had been fixed (10\% formaldehyde solution) before the beginning of this study.

Dissections conducted on the hearts included the removal of the epicardium and subepicardial adipose tissue and the tracing of each artery and its branches. The dissection continued with detailed preparation of coronary arteries. The dissection of the ascending aorta and coronary arteries' origins was performed by stereoloupe. The ascending aorta was transversally sectioned approximately $1 \mathrm{~cm}$ above the commissures of the aortic leaflets. After that, the aorta was longitudinally opened at the level of the posterior aortic sinus (noncoronary sinus) to enable the visualization and analysis of the right and left aortic leaflets and their respective coronary ostia. The most representative preparations were photographed. The lengths and diameters of the coronary arteries were made using a nonius (up to an accuracy of $1 \mathrm{~mm}$ ) and the angles between the arteries and great vessels were measured using a goniometer (up to an accuracy of 1 degree).

The coronary arterial network obtained for each heart was diagramed. Standard methods of descriptive and analytic statistics were used to obtain the average values, the standard deviations and the results of t-tests for small and non-dependent samples.

\section{RESULTS}

Eight out of 23 hearts (34.8\%) included in this study had the aortic origin of the conal artery (Fig.1). The rest of preparations $(65.2 \%)$ had conal artery arising from the proximal part of the RCA as its first ventricular branch. The difference in the frequency of the TCA between the sexes was statistically insignificant $(\mathrm{p}>0.05)$.

The external diameter of the RCA at its aortic origin was $5.5 \pm 1.2 \mathrm{~mm}$ (ranged from 3.4 to $7.6 \mathrm{~mm}$ ) in the specimens without the TCA. The average value of the RCA external diameter was $4.7 \pm 1.2 \mathrm{~mm}$ (ranged from 4.0 and $5.6 \mathrm{~mm}$ ) in the specimens with the TCA. The difference between these external diameters was statistically insignificant ( $p>0.05$ ).

The external diameter of the TCA averaged $1.7 \pm 0.3 \mathrm{~mm}$ (varied from $1.2 \mathrm{~mm}$ to $2.1 \mathrm{~mm}$ ). The external diameter of the conal branch of the RCA had an average value of $2.2 \pm 0.7 \mathrm{~mm}$ (varied from 1.2 to $3.5 \mathrm{~mm})$. The difference between these external diameters was statistically insignificant ( $p>0.05$ ), as presented in Table 1.

The ratio of external diameters of the RCA and TCA was approximately $2.8 \pm 0.8$, while the ratio of the external diameters of the RCA and its conal branch was $2.6 \pm 0.7$. The difference between these ratios was also not statistically significant $(\mathrm{p}>0.05)$, as presented in Table 2.

In all the specimens, the ostium of the TCA was in the right aortic sinus, superior and to the left of the ostium of the RCA, with average diameter of $1.3 \pm 0.6 \mathrm{~mm}$ (Fig 2). The average distance between the TCA and RCA ostia was $1.7 \pm 0.6 \mathrm{~mm}$ (varied from 1.0 to $2.7 \mathrm{~mm}$ ).

The angle between the longitudinal axes of the TCA and aorta showed values from $30^{\circ}$ to $135^{\circ}$ with average

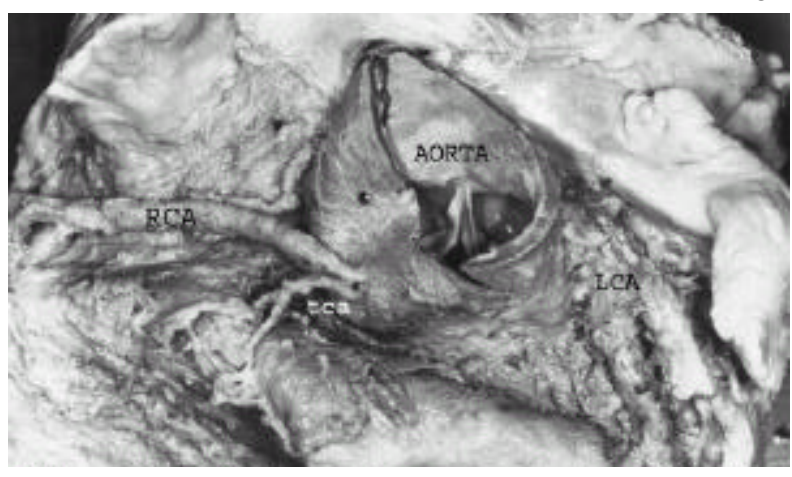

Figure 1. Three coronary arteries arising from aorta (superior view) TCA, third coronary artery; RCA,right coronary artery; LCA, left coronary artery 
Table 1. External diameters of the RCA, TCA and Conal branch

\begin{tabular}{lll}
\hline & $\begin{array}{l}\text { External } \\
\text { Diameter }\end{array}$ & $\begin{array}{l}\text { Difference in } \\
\text { Diameter }\end{array}$ \\
\hline $\begin{array}{l}\text { RCA without } \\
\text { the TCA }\end{array}$ & $5.5 \pm 1.2 \mathrm{~mm}$ & Insignificant $(\mathrm{p}>0.05)$ \\
$\begin{array}{l}\text { RCA with } \\
\text { the TCA }\end{array}$ & $4.7 \pm 1.2 \mathrm{~mm}$ & Insignificant $(\mathrm{p}>0.05)$ \\
TCA & $1.7 \pm 0.3 \mathrm{~mm}$ & Insignificant $(\mathrm{p}>0.05)$ \\
$\begin{array}{l}\text { Conal branch } \\
\text { of the RCA }\end{array}$ & $2.2 \pm 0.7 \mathrm{~mm}$ & Insignificant $(\mathrm{p}>0.05)$ \\
\hline
\end{tabular}

RCA, right coronary artery; TCA, third coronary artery.

Table 2. The ratio of external diameters of the RCA and TCA and the ratio of external diameters of the RCA and its Conal branch

\begin{tabular}{lll}
\hline & Ratio of Diameters & Difference in Ratio \\
\hline RCA and TCA & $2.8 \pm 0.8$ & Insignificant $(\mathrm{p}>0.05)$ \\
$\begin{array}{l}\text { RCA and Conal } \\
\text { branch }\end{array}$ & $2.6 \pm 0.7$ & Insignificant $(\mathrm{p}>0.05)$ \\
\hline
\end{tabular}

RCA, right coronary artery; TCA, third coronary artery.

value of $73.4^{\circ} \pm 35.2^{\circ}$ (Table 3 ).

The TCA ran over the arterial conus immediately after its arising from the ascending aorta. After the short path, it divided into two ending branches. These ending branches formed a gentle arterial ring with the left conal branch in $50 \%$ of preparations with the TCA (Fig. 3). The left conal branch, in all cases, was a right, side branch of the left anterior descending branch (LAD) of the LCA. In one of the preparations, a terminal branch of the TCA had a myocardial bridge (Fig. 4).

The number of branches (side and ending) of the TCA varied from two to seven as follows: two branches were observed in 5 out of 8 hearts $(62.5 \%), 3$ branches were observed in 2 out of 8 hearts ( $25 \%)$ and 7 branches were observed in 1 out of 8 hearts $(12.5 \%)$.

The TCA always terminated by division into two

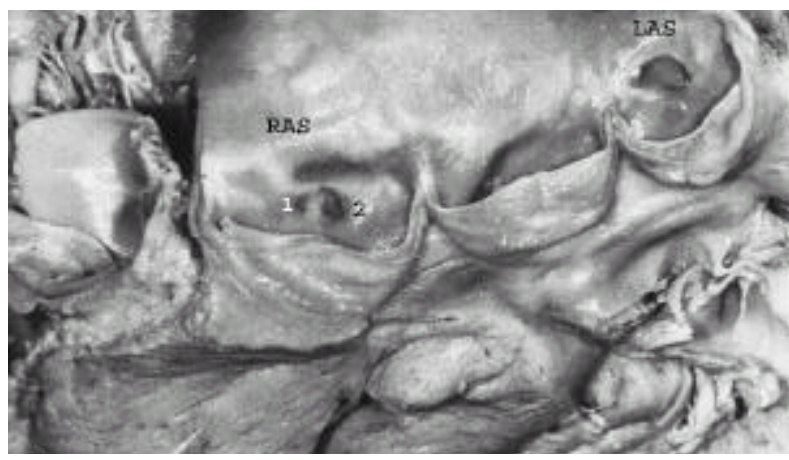

Figure 2. Interior view of aortic bulbus, showing two orifices in the right aortic sinus. RAS, right aortic sinus; 1, third (conal) artery; 2, right conal artery; LAS, left aortic sinus.
Table 3. The angles between the TCA and aorta and the RCA and Conal branch

\begin{tabular}{lll}
\hline & Angle & Difference in Angle \\
\hline TCA and aorta & $73.4^{\circ} \pm 35.2^{\circ}$ & Insignificant $(\mathrm{p}>0.05)$ \\
$\begin{array}{l}\text { RCA and Conal } \\
\text { branch }\end{array}$ & $82.3^{\circ} \pm 39.8^{\circ}$ & Insignificant $(\mathrm{p}>0.05)$ \\
\hline
\end{tabular}

RCA, right coronary artery; TCA, third coronary artery.

branches.

The conal artery, rising from the proximal segment of the RCA, showed an almost identical path, had similar number of branches and a branching pattern to the TCA. It formed anastomosis with the left conal branch more often (63\% of preparations having the conal branch) than the TCA.

The distance from the point of the RCA arising from the aorta to the point of the conal branch arising from the RCA was on the average $3.4 \pm 1.8 \mathrm{~mm}$ (ranged from1.6 to $7.3 \mathrm{~mm}$ ).

The angle between longitudinal axes of the RCA and conal branch was about $82.3^{\circ} \pm 39.8^{\circ}$, with variations between $42^{\circ}$ and $157^{\circ}$ (Table 3 ).

\section{DISCUSSION}

The variations of the number of coronary arteries are not rare and could cause certain clinical consequences. There were described cases of single coronary artery arising either from the right $(7)$ or left $(8,9)$ aortic sinus. The presence of single coronary artery might be associated with sudden death, myocardial ischemia, or congestive heart failure $(7,8)$. The exact incidence of these associated clinical events is not yet known $(10,11)$. There are no data that the supernumerary coronary artery could be advantageous or detrimental when compared to the classical coronary scheme-right and left coronary arteries originating from the aortic sinuses (11).

Different populations showed variations in the incidence of the supernumerary coronary artery. The

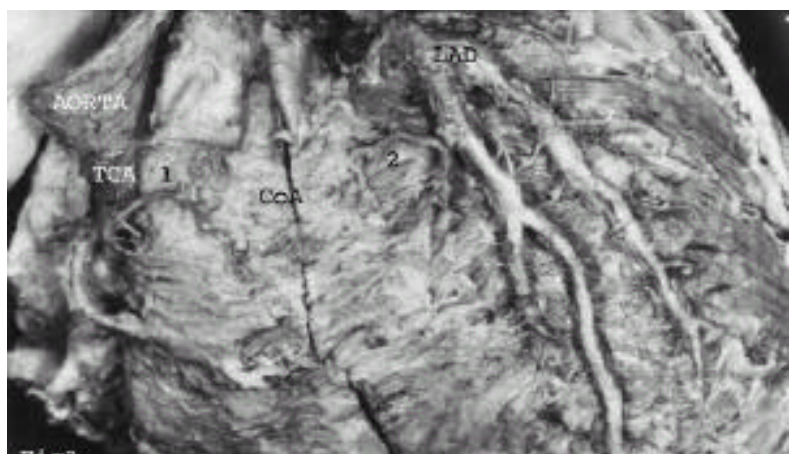

Figure 3. Sternocostal surface of the heart showing left and right conal artery, without anastomosis. TCA, third coronary artery; 1, branch of TCA; LAD, left anterior descending branch of left coronary artery; 2 , left conal artery; $\mathrm{CoA}$, conus arteriosus. 


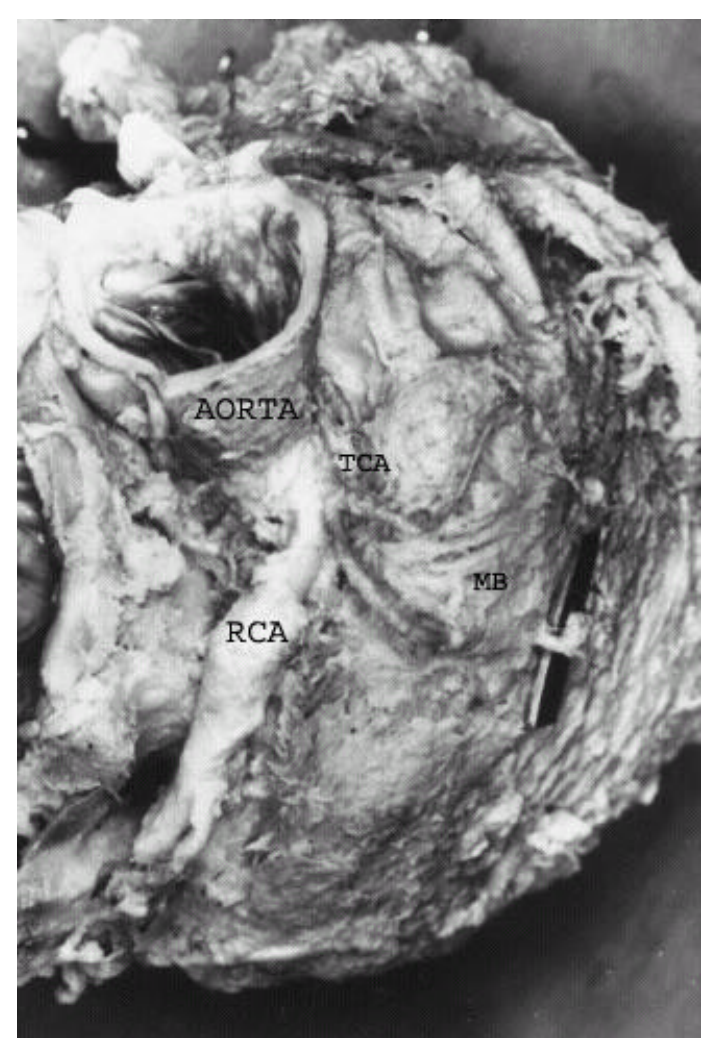

Figure 4. Myocardial bridge over the one of the branches of the third coronary artery. RCA, right coronary artery; TCA, third coronary artery; MB, myocardial bridge.

lowest incidence of the supranumeral coronary artery was $8 \%$ (12) in Iraqi population, while the highest incidence was $50 \%(13,14)$. Similar results, to those obtained in our research, were also found in the literature (15).

It was concluded by other authors that the vascularization area of the conal artery did not depend on its origin $(1,2,12)$. Instead it was proposed that the length of the conal artery determined its physiological significance. The absence of ST segment elevation in lead V1 of ECG during anterior acute myocardial infarction might suggest that the interventricular septum was protected by a large conal branch (angiographically proved) in addition to the septal branches of the left anterior descending artery-double circulation (16).

Gupta SK et al. (17) described a case of two vessels arising from the right coronary sinus from two separate ostia. The smaller vessel gave off the sinoatrial nodal branch and the posterior descending artery whereas the larger one gave off the conus branch, the right ventricular branches, and continued as acute marginal branch. According to results of our investigation, the supernumerary (third) coronary artery formed Vieussens' arterial ring in 50\% of the cases with the TCA, while the conal branch of the RCA formed the anastamosis at a higher frequency, in $63 \%$ of the cases with the conal branch. This anastomosis was considered an important collateral path between the left and right coronary arteries $(1,2)$. The results of our research have led us to conclude that the presence of a supernumerary coronary artery might reduce the anastomotic potential of the RCA.

No significant difference was observed $(p>0.05)$ between the angle formed by the TCA and aorta (on the average $82^{\circ}$ ) and the one between the RCA and its conal branch (on the average $73^{\circ}$ ). The similar value of the latter $\left(79.6^{\circ}\right)$ was also found by other authors (1). The distance between the osthia of the RCA and TCA in the right aortic sinus was only $1.7 \pm 0.6 \mathrm{~mm}$. In light of these results and the leading theory of the coronary arteries' development $(3,18)$, it could be hypothesized that the TCA developed as a result of incorrect growth of the embryological Vieussens' circle into the aorta.

Hutchins et al. (4) concluded that coronary arteries' ostia originated from sinuses of Valsalva where wall tension was increased by a saddle-shaped configuration. The unknown factors that interfered with wall tension of the aortic sinuses could promote development of anomalous coronary arteries' ostia.

Certain authors proposed that some coronary arterial patterns were not fully established at the time of birth. The existence of multiple orifices and the fact that human adult hearts had a higher incidence than human fetal hearts suggested could lead us to conclude that the third coronary artery developed after birth $(19,20)$.

Based solely on the TCA's morphological features and its vascularisation area, there is insufficient evidence to suggest that the TCA per se could provoke any known clinical or disease state.

\section{ACKNOWLEGEMENTS}

We would like to thank Ass. Prof. Dr. Valentina Nikolic, M.D. for generous assistance during this research.

\section{REFERENCES}

1. Pejkovic B, Bogdanovic D. Arterije i vene srca. Savremena administracija. Beograd, 1995. p. 8-21.

2. Hadziselimovic H. Krvni sudovi srca. Jugoslovenska medicinska naklada. Zagreb, 1980. p.21-27.

3. Bogers AJ, Gittenberger-de Groot AC, Poelmann RE, Peault BM, Huysmans HA Development of the origin of the coronary arteries, a matter of ingrowth or outgrowth? Anat Embryol (Berl). 1989;180(5):437-41.

4. Hutchins GM, Kessler-Hanna A, Moore GW Development of the coronary arteries in the embryonic human heart. Circulation 1988 Jun;77(6):1250-7.

5. Katsumi Ando, Yuji Nakajima, Toshiyuki Yamagishi, Sadamu Yamamoto, Hiroaki Nakamura. Development of Proximal Coronary Arteries in Quail Embryonic Heart. Circulation Research. 2004;94:346.

6 .CoroneP, CoroneA, DorX, Binet JP. Coronary arteries and their variations. An embryological explanation C R Acad Sci III. 
1984;299(11):451-8.

7. Benslimane A, Funck F, Bellorini M, Lefevre T, Guillard N, Jacoly CJ.Single coronary artery arising from the right coronary sinus.Report of two cases.Arch Mal Coeur Vaiss. 1998 Dec;91(12):1503-7.

8. Takano M, Seimiya K, Yokoyama S, Okamatsu K, Ishibashi F, Uemura R, Hata N, Mizuno K. Unique single coronary artery with acute myocardial infarction: observation of the culprit lesion by intravascular ultrasound and coronary angioscopy. Jpn Heart J. 2003 Mar;44(2):271-6.

9. Koizumi M, Kawai K, Honma S, Kodama K.Anatomical study of a left single coronary artery with special reference to the various distribution patterns of bilateral coronary arteries. Ann Anat. 2000 Nov;182(6):549-57.

10. Becker AE: Congenital coronary arterial anomalies of clinical relevance. Coron Artery Dis 1995 Mar; 6(3): 187-93.

11. Cieslinski G, Rapprich B, Kober G: Coronary anomalies: incidence and importance. Clin Cardiol 1993 Oct; 16(10): 711-5.

12. Kurjia HZ, Chaudhry MS, Olson TR. Coronary artery variation in native Iraqi population.Cathet Cardiovasc Diagn. 1986; 12(6):386-90.

13. Schlesinger MJ, Zoll PM and Wessler S (1949). The conus artery: A third coronary artery. Am Heart J, 38: 823-836.
14. Waller B.F, Schlant R.C. Anatomy of the Heart, Hurst's The Heart. McGraw-Hill, London, 1986. p. 84-86.

15. Vilallonga JR. Anatomical variations of the coronary arteries: The most frequent variations. Eur J Anat. 2003; 7 Suppl. 1: 2941.

16. Ben-Gal T, Sclarovsky S, Herz I, Strasberg B, Zlotikamien B, Sulkes J, Birnbaum Y, Wagner GS, Sagie A. Importance of the conal branch of the right coronary artery in patients with acute anterior wall myocardial infarction: electrocardiographic and angiographic correlation. J Am Coll Cardiol. 1997 Mar 1;29(3):506-11.

17. Gupta SK, Abraham AK, Reddy NK, Moorthy SJ.Supernumerary right coronary artery.Clin Cardiol. 1987 Jul; 10(7):425-7.

18. Conte G, Pellegrini A. On the development of the coronary arteries in human embryos, stages 14-19. Anat Embryol (Berl). 1984;169(2):209-18.

19. Miyazaki M, Kato M. Third coronary artery: its development and function. Acta Cardiol. 1988;43(4):449-57.

20. Edwards BS, Edwards WD, Edwards JE. Aortic origin of conus coronary artery. Evidence of postnatal coronary development. Br Heart J. 1981 May; 45(5):555-8.

Ivan Stankovic has just finished the 6th year at Belgrade School of Medicine. He will be applying for postgraduate studies in vascular surgery. During his medical studies, he was awarded for special achievements at Belgrade University twice. In addition, his scientific reports were awarded at the International Medical Student's Conferences in Sofia (Bulgaria, 2003.) and Timisoara (Romania, 2004. together with M. Jesic). He has teaching experience as a student demonstrator at Institute of Anatomy in Belgrade.

Milica Jesic is a 5th year medical student of Belgrade University. Her areas of interest include research in the anatomy of coronary arteries and coronary arteriography. She worked as a student demonstrator at the Institute of Anatomy University of Belgrade for two years during her medical studies. She hopes to get into a residency program in cardiology at Belgrade University. 